\title{
Fall, resurrection and uncertainty: an Arabian tale
}

\author{
MARTIN FISHER
}

In the first issue of volume 1 of Oryx the call went out for 'articles showing what is being attempted to preserve wild life, where success is achieved and where a reverse is sustained' (Anon., 1950, p. 4). The readership responded enthusiastically to this call and now, here in volume 50, continues to respond. No tale better tells of the struggle to conserve than that of the Arabian oryx Oryx leucoryx, once a species in free fall but now resurrected throughout much of its former range. The efforts to prevent its extinction-reported extensively in this journal - are an exemplar of the work to conserve individual species.

In 1952 Foster-Vesey-Fitzgerald (p. 232) lamented the decline of the fauna of Arabia:

The surprising fact is that any form of wildlife has been able to exist in such utterly waterless places. Yet up to the beginning of the present century an interesting assemblage of animals existed in the Arabian desert. Even when modern rifles came into general use the species held their own in the vast spaces to a very satisfactory extent. But the last decade has witnessed the advent of a shocking predator, namely the Mighty Jeep. It cannot be long now before motorized hunting parties will sweep Arabia's fauna into uttermost corners, where a subsequent drought will whiten its bones.

He further remarked that the Arabian oryx was by then extinct in the Great Nafud, in the north, although apparently still extant in the southern Rub al Khali. In the next mention of the species, Talbot (1960) documented the use of 'both surface vehicles and airplanes' (p. 241) in hunting, and estimated that 100-200 oryx remained in the southern Rub al Khali. He correctly predicted that it is probably only a matter of a few years at most until the wild Arabian oryx is totally exterminated' (p. 241), and concluded that 'the only way to assure survival of this interesting species is to transfer some. . to a safer habitat' (p. 246).

Reports in December 1960 of a major hunt of oryx in the Yemen-Oman border region galvanized the then Fauna Preservation Society-now Fauna \& Flora Internationalinto action: Operation Oryx was born. Under the leadership of Ian Grimwood (Anon., 1991), then chief game warden of Kenya, the Operation involved team members from Kenya, Yemen and the UK, knowledgeable and indispensable Bedouin, and prior practice catching Oryx beisa in Kenya. Despite broken gearboxes, and ribs, and other travails, the Operation captured four oryx-three males, one of which died, and a female-in eastern Yemen in April 1962 (Grimwood, 1962). They were flown to Kenya, and a mating and pregnancy followed in captivity (Anon., 1963a).

The captured oryx were later flown to Phoenix Zoo in Arizona and, together with oryx provided by the rulers of

Martin Fisher Fauna \& Flora International, Cambridge, UK

E-mail martin.fisher@fauna-flora.org
Saudi Arabia and Kuwait, and London Zoo (the latter a young female that had been captured in Oman as a calf), totalled four males and five females (Anon., 1963c; Grimwood, 1964, 1967). Fitter (1967) noted that 'ungulates are without a doubt the easiest of the larger mammals to breed in captivity' (p. 92) and that the World Herd, as it became known, of Arabian oryx had by then increased to 16 . Grimwood (1967) later reflected that cooperation had been key to the success of Operation Oryx, with capture and the subsequent compilation of the World Herd involving 'six governments, five zoos, a score of societies and major commercial organisations, and hundreds of private individuals in Arabia, Africa, Europe and America' (p. 116).

Subsequently, reports were received of extant wild oryx in the eastern Rub al Khali and on the Jiddat al Harasis of Oman (Anon., 1963C, 1965a,b; Grimwood, 1964). But in October 1972, with the help of the Harasis tribe, the remains of three recently dead oryx were found on the Jiddat al Harasis, with evidence of the live capture of four more: these 'oryx killed and captured could well have been the last wild Arabian oryx' (Henderson, 1974, p. 350).

By 1972 the World Herd numbered 32 (Turkowski, 1972); individuals were later moved to other collections in the USA and Europe (Fitter, 1980). Other than the World Herd there were also substantial numbers of Arabian oryx in zoos and private collections in Arabia (Fitter, 1980). Preparations began for the first reintroductions. By 1977 the Royal Society for the Conservation of Nature in Jordan had set up a captive breeding unit at its fenced Shaumari Reserve (Clarke, 1977), which eventually received 11 founding Arabian oryx from the World Herd and Qatar (Harding et al., 2007). A feasibility study in Oman recommended that oryx be reintroduced to the Jiddat al Harasis, noting that 'the Harasis would whole-heartedly support a reintroduction programme' (Jungius, 1978, p. 335). The reintroduction began with the arrival of oryx from the World Herd in 1980 (Fitter, 1980) and in 1982, following acclimatization, 10 Arabian oryx were released into the wild on the Jiddat al Harasis (Fitter, 1982). They were followed by a second herd, of eight, in 1984, by which time the first herd had increased to 13 (Fitter, 1984).

In Saudi Arabia oryx originating from the World Herd and from three other collections were reintroduced to the $2,244 \mathrm{~km}^{2}$ fenced Mahazat as Sayd protected area in the south-west, from 1990, and to the c. $12,000 \mathrm{~km}^{2}$ 'Uruq Bani Ma'arid protected area in the western Rub al Khali, from 1995 (Thouless, 1991; Ostrowski et al., 1998). By 1998 these populations numbered c. 350 and 130 , respectively (Ostrowski et al., 1998). The 'Uruq Bani Ma'arid population 
was the first established in an unfenced area beyond Oman. With the two populations in Saudi Arabia thriving, attention turned to the study of the species' ecology and management (Seddon \& Ismail, 2002; Seddon et al., 2003; van Heezik et al., 2003).

Despite tribulations experienced as a very small population, the reintroduced population on the Jiddat al Harasis also thrived and by 1990 the wild population was $>100$, ranging over c. 11,000 km² (Spalton et al., 1999). Remoteness and the role of substantial seasonal fog in ensuring year-round, albeit sparse, grazing secured the importance of the reintroduction area for conservation: in 1994 the area was inscribed, as the Arabian Oryx Sanctuary, on the World Heritage List. In 1996, however, poaching resumed-ironically for live collections outside Oman-although despite the loss of at least 27 individuals the population was c. 400 at the year's end (Spalton et al., 1999). But sadly poaching intensified and by late 1998 the population was $<140$; some of the remaining oryx were therefore captured, and guarded in the same enclosure, now expanded, from which the first herds had been released (Spalton et al., 1999). By 2007 the wild population had further decreased and a c. $90 \%$ reduction in the size of the area protected, to support oil exploration, resulted in the Sanctuary being the first World Heritage Site to be delisted.

Throughout these vagaries $O$. leucoryx was categorized as Endangered on successive versions of the Red List up to 2008. By 2011, however, there were c. 1,000 in semi-wild and wild populations in Oman, Saudi Arabia, the United Arab Emirates, Israel and Jordan, and 6,000-7,000 in captivity. The desired 'mass production' of oryx (Grimwood, 1967, p. 118) had been successful. With the global population assessed as stable or increasing, the species was recategorized as Vulnerable (IUCN SSC Antelope Specialist Group, 2011).

Despite setbacks, the various Arabian oryx reintroduction programmes demonstrated that a large ungulate on the verge of extinction could be captured in remote and difficult terrain, bred successfully in captivity, and reintroduced to the wild. Operation Oryx, which began it all, expended GBP 4,625 11s. 1d. (Anon., 1963b), equivalent to c. GBP 88,000 today, or c. GBP 29,300 per oryx. Although oryx from elsewhere were also used to breed for reintroduction, the inspiration provided by the Operation may be judged good value.

The current Vulnerable categorization suggests an improved conservation status, yet most of the sites included in the 2011 assessment have had to be fenced (Mallon \& Stanley Price, 2013). Once again, oryx no longer roam wild on the Jiddat al Harasis-uncertainty has returned to this Arabian tale. As Spalton et al. (1999, p. 175) noted, the 'challenge of today is neither captive breeding nor reintroduction but to protect the species in the wild'.

This Editorial and the references cited herein are freely available as a virtual issue of the journal at http://journals. cambridge.org

\section{Acknowledgements}

I thank Andrew Spalton, Bill Adams, Cella Carr, David Mallon, Maria Luisa de Castro Fisher, Mark Stanley Price, Philip Seddon and Yolanda van Heezik for their critiques.

\section{References}

Anon. (1950) Editorial-Notes. Oryx, 1, 4-10.

Anon. (1963a) Editorial Notes. Oryx, 7, 1-8.

Anon. (1963b) The Auditor's Report. Oryx, 7, 50-56.

Anon. (1963c) Editorial Notes. Oryx, 7, 57-66.

Anon. (1965a) Notes and News. Oryx, 8, 75-82.

Anon. (1965b) Notes and News. Oryx, 8, 147-155.

Anon. (1991) Ian Grimwood, 1912-1990. Oryx, 25, 118-120.

Clarke, J. (1977) Reserve for Arabian Oryx. Oryx, 14, 31-35.

FitTER, R.S.R. (1967) Conservation by captive breeding: a general survey. Oryx, 9, 87-96.

Fitter, R.S.R. (1980) Operation Oryx-end of phase one. Oryx, 15, 227.

Fitter, R.S.R. (1982) Arabian oryx returns to the wild. Oryx, 16, 406410.

FitTer, R.S.R. (1984) Operation Oryx-the success continues. Oryx, $18,136-137$.

Foster-Vesey-Fitzgerald, D. (1952) Wild life in Arabia. Oryx, 1, 232-235.

Grimwood, I.R. (1962) 'Operation Oryx'. Oryx, 6, 308-334.

Grimwood, I.R. (1964) 'Operation Oryx': the second stage. Oryx, 7 , 223-225.

Grimwood, I.R. (1967) Operation Oryx: the three stages of captive breeding. Oryx, 9, 110-118.

Harding, L.E., Abu-Eid, O.F., Hamidan, N. \& al Sha'lan, A. (2007) Reintroduction of the Arabian oryx Oryx leucoryx in Jordan: war and redemption. Oryx, 41, 478-487.

van Heezik, Y., Ismail, K. \& Seddon, P.J. (2003) Shifting spatial distributions of Arabian oryx in relation to sporadic water provision and artificial shade. Oryx, 37, 295-304.

Henderson, D.S. (1974) Were they the last Arabian oryx? Oryx, 12, 347-350.

IUCN SSC Antelope Specialist Group (2011) Oryx leucoryx. The IUCN Red List of Threatened Species 2013. Http://dx.doi.org/10.2305/ IUCN.UK.2011-1.RLTS.T15569A4824960.en [accessed 1 December 2015].

Jungius, H. (1978) Plan to restore Arabian oryx in Oman. Oryx, 14, 328-336.

Mallon, D.P. \& Stanley Price, M.R. (2013) The fall of the wild. Oryx, 47, 467-468.

Ostrowski, S., Bedin, E., Lenain, D.M. \& Abuzinada, A.H. (1998) Ten years of Arabian oryx conservation breeding in Saudi Arabiaachievements and regional perspectives. Oryx, 32, 209-222.

SEDDON, P.J. \& ISMAIL, K. (2002) Influence of ambient temperature on diurnal activity of Arabian oryx: implications for reintroduction site selection. Oryx, 36, 50-55.

Seddon, P.J., Ismail, K., Shobrak, M., Ostrowski, S. \& Magin, C. (2003) A comparison of derived population estimate, markresighting and distance sampling methods to determine the population size of a desert ungulate, the Arabian oryx. Oryx, 37, 286294.

Spalton, J.A., Lawrence, M.W. \& Brend, S.A. (1999) Arabian oryx reintroduction in Oman: successes and setbacks. Oryx, 33, 168-175.

Tацвот, L.M. (1960) A look at threatened species. Oryx, 5, 155-293.

Thouless, C. (1991) Conservation in Saudi Arabia. Oryx, 25, 222-228. Turkowski, F.J. (1972) Arabian oryx at Phoenix. Oryx, 11, 332. 